\title{
Cengestao
}

\section{Mídias sociais, violência contra mulheres e informação: prospecção do campo à luz das humanidades digitais}

\author{
Nathália Lima Romeiro \\ Mestra; Universidade Federal de Minas Gerais, Minas Gerais, MG, Brasil; \\ ntromeiro91@gmail.com; ORCID: http://orcid.org/0000-0002-6274-4839 \\ Ricardo Medeiros Pimenta \\ Doutor, Instituto Brasileiro de Informação em Ciência e Tecnologia, Rio de Janeiro, RJ, Brasil; \\ ricardopimenta@ibict.br; ORCID: https://orcid.org/0000-0002-1612-4126
}

\begin{abstract}
Resumo: Este trabalho discute o fenômeno das hashtags nas mídias sociais digitais como uma estratégia para discussão das performances de gênero e oposição à violência contra mulheres. Busca o referencial teórico e metodológico das Humanidades Digitais associado àqueles da Ciência da Informação e dos estudos de gênero a partir da coleta de dados relacionados a postagens indexadas com as hashtags \#primeiroassedio, \#meuprimeiroassedio e \#mexeucomumamexeucomtodas na mídia social Facebook. Apresenta resultados caracterizados como "fotos", "vídeo", "relato", "notícias" e "outros". Identifica a categoria fotos a que mais recebia interações e compartilhamentos no Facebook; o que nos leva ao conceito de visibilidade informacional. Compreende-se a importância de pesquisas com recorte de gênero, a partir da Ciência da Informação e das Humanidades Digitais, ao passo que se mantenham abertas as possibilidades de discussão de uma temática sensível não somente para Mulheres como para demais estratégias de formação de redes de apoio, afeto e empoderamento social.
\end{abstract}

Palavras-chave: Violência contra mulheres. Mídias sociais. Humanidades Digitais. Hashtags. Estudos de Gênero.

\section{Introdução}

A suposta desintermediação da informação ocorrida pelos recursos tecnológicos computacionais e digitais propiciaram aos que detém o privilégio do acesso à internet mais possibilidades de interação com as informações e dados que ali existem ora produzindo-os, ora compartilhando-os. Com efeito, tal campo de possibilidades não está isento de problemas. A exposição de indivíduos em redes sociais, suas respectivas mídias, por exemplo, trazem a seu reboque uma 
amplificada e convergente heteroglossia onde solidariedade assim como violências tomam lugar em um palco/plataforma por meio das expressões escrita, oral e imagética.

Este artigo trata de refletir sobre tais formas de violência sexual expressas em redes sociais contra as mulheres de uma maneira descritivoexploratória, tendo como foco a correlação da abordagem metodológica de coleta de dados nessas mídias sociais, relacionados à violência sexual contra mulheres, com o campo das Humanidades Digitais (HD) que vem sendo mais e mais explorado por nossos colegas pesquisadores da Ciência da Informação $(\mathrm{CI})$.

Nosso intuito é identificar o tipo de método utilizado, considerando-o como algo que, se já utilizado na CI, do ponto de vista de estudo sobre hashtags, sobre redes sociais e usuários da informação, por outro lado, também traz consigo um apelo humanístico indelével, já que questões de gênero e violência têm seu germe referencial nas ciências humanas mais tradicionais. O "entroncamento" dessas duas perspectivas nos convidam a pensar sobre o potencial dos métodos digitais nas humanidades e, nesse sentido, na CI. Sendo assim, falar sobre HD se faz tempestivo uma vez que esse mesmo entroncamento já é claramente identificado por alguns pesquisadores da CI, como Ricardo Pimenta (2020), enquanto um lugar comum e de interseção entre campos de pesquisa distintos, mas que detém particularidades comuns.

Partimos do princípio de que o desenvolvimento das tecnologias de informação e comunicação (TIC), potencializadas pela conexão global e suas gramáticas algorítmicas, tornam as fronteiras entre as disciplinas das ciências humanas, sociais e sociais aplicadas cada vez mais permeáveis. Nesse sentido, buscamos a partir da contextualização do nosso objeto e de sua respectiva temática, contribuir para uma reflexão contínua sobre como a CI pode continuamente desenvolver-se em escala interdisciplinar tendo em perspectiva o campo das HD em franca expansão no cenário brasileiro. Para tal, entendemos necessária a aproximação realizada a partir desse artigo, enquanto fração de uma dissertação de mestrado defendida sobre o tema da violência sexual nas redes 
sociais, sob a lente de uma abordagem descritivo-exploratória, da pesquisa realizada com as práticas familiares às HD.

Nossa contribuição à guisa mais conclusiva tem como intento lançar uma reflexão sobre como, em uma perspectiva de HD, poderíamos desenvolver protocolos, métodos capazes de auxiliar a pesquisa em mídias sociais voltada a questões sensíveis circunscritas no contexto de estudos de gênero, sexualidade, ou até mesmo sociais no tocante às interações de indivíduos mediados pelas atuais redes sociais digitais.

Métodos empregados nesses dois campos são mais comuns do que o esperado, conforme Lyn Robinson, Ernesto Priego e David Bawden (2010)ํㅜ,

Uma integração entre o BCI e as correntes de HD que têm um interesse explícito nos componentes da cadeia de informação parece oferecer um futuro promissor para ambas as disciplinas. Não apenas consolida uma aliança natural entre disciplinas com preocupações e perspectivas semelhantes, (...) mas permite novas abordagens de pesquisa na interface das duas disciplinas. Exemplos desta última são a ampliação da bibliometria e estudos com enfoque em HD para proporcionar uma visão mais profunda (Sula, 2012) e análise das mídias sociais, com os mesmos benefícios (ROBINSON, PRIEGO, BAWDEN, 2015, p. 51). ${ }^{2}$

Já Tibor Koltay (2016) aponta que:

Tanto BCI quanto HD podem ser considerados como "ciências da informação", ou seja, disciplinas que estão interessadas no estudo da informação (...) HD está lutando para entender os efeitos de uma crescente infraestrutura digital como um sistema de produção de conhecimento nas ciências humanas. Tal pensamento pode ser estendido ao ato de olhar o componente digital do HD pensando criticamente sobre os caminhos sobre como o conhecimento no século XXI é transformado em informação através de técnicas computacionais. Neste processo, os dispositivos computacionais exigem que um determinado objeto seja traduzido para os códigos digitais que o computador possa compreender. (...) Este objetivo não é apenas significativo, mas fundamental para ambas as disciplinas (KOLTAY, 2016). ${ }^{3}$

De forma complementar, Ricardo Pimenta (2020) também afirma que: 
A CI parece dar sinais de que suas pesquisas cada vez mais demandam um diálogo amplo e profundo sobre as implicações sociotécnicas, tecnopolíticas e culturais presentes em suas pesquisas; criando assim uma demanda crescente pela perspectiva humanística em seus ensaios e demais investigações. Ela, a CI, já domina certas expertises como aquelas da organização do conhecimento, taxonomias, da preservação e recuperação da informação. São tais atividades, entre tantas outras, que garantem a manutenção e o funcionamento de projetos vistos como "mirabolantes" oriundos das HD. (...) as HD apresentam características relevantes para pensarmos nelas enquanto uma espécie de "hipercampo" - transdisciplinar desde sua origem —, onde aspectos outrora singulares, de campos específicos das Ciências Humanas e das Exatas, se remodelam de forma tautócrona com fins comuns apesar de objetivos diversos. E que é nesse hipercampo que a CI se faz presente além de essencial para a conclusão de tais objetivos. (PIMENTA, 2020).

Percebe-se, assim, que entre todos estes autores, o ponto convergente é o das similaridades entre as HD e a CI. No Brasil, ao buscarmos fundamento nesses dois campos, queremos identificar as especificidades de registros e compartilhamentos de práticas de violência contra as mulheres nas mídias sociais e refletir sobre possíveis demandas em torno da produção de novas formas de métricas para esses novos registros sociais mediados pelas plataformas sociais. Queremos também lançar questionamentos oriundos das Humanidades tradicionais sobre os problemas informacionais contemporâneos. Com isso, identificar e manifestar o potencial papel das HD enquanto uma oportunidade de desenvolvimento de novas perspectivas e iniciativas (BAYLEY, 2011), para se pensar as formas de ódio pelas minorias expressas pelas TIC, entendendo seu fundamental papel para a continuidade das pesquisas em CI.

\section{Interação social e mídias sociais digitais}

Apesar de nem todas as pessoas do mundo terem acesso a computadores, podemos dizer que grande parte da população global acessa algum tipo de aparelho tecnológico digital conectado à internet (banda larga, 3G/4G ou até mesmo internet discada). Entretanto, a facilidade que hoje muitos de nós - 
consumidores privilegiados, minoria em termos numéricos, mas maioria em termos de concentração de capitais simbólicos, culturais e materiais conhecemos em relação a conexão com a internet e suas diversas possibilidades de uso na web, especialmente a partir da web 2.0, representa também o canal amplificador por onde excessos e violências de toda sorte redefinem nossos "mapas" do real atacando, expondo e vitimando populações e sujeitos sociais mais vulneráveis.

De acordo com Alex Primo (2007, p. 2) a web 2.0 tem repercussões sociais importantes, que potencializam processos de trabalho coletivo, de troca afetiva, de produção e circulação de informações, de construção social de conhecimento apoiada pela informática”.

Potencializou o trabalho coletivo assim como redefiniu, e redefine, formas de compra e venda de produtos e serviços. O mercado e a exposição de produtos, de pessoas e de discursos apontam para uma questão de performance. Coletivos e indivíduos também performam. Ser mulher e "sobreviver" em uma sociedade majoritariamente heteronormativa e misógina, é performar resistência e resiliência em um "campo minado". Campo este que expõe suas minorias de forma ostensiva.

O que se (in)forma pelo discurso cotidiano do agressor que se faz visível e tangível pela web e suas plataformas sociais ainda pode, infelizmente, atualizar a performatividade de um conhecimento masculino algoz. Ainda assim, o que se mantém na maioria das vezes, nos termos da memória sobre o advento da Internet e seus novos mecanismos de redefinição do social mediatizado pelo digital, é que no tocante à troca de informações e a construção social dos conhecimentos, canais de comunicação como jornais, blogs, repositórios, bases de dados, revistas científicas, etc. ganharam maior visibilidade, concorrência e rapidez na divulgação de conteúdos nesta nova web.

Deixamos por último a troca afetiva pois esta encontra-se diretamente ligada às redes sociais e mídias sociais digitais. Cabe, portanto, diferenciar os conceitos de redes sociais e mídias sociais. De acordo com a pesquisadora Regina Marteleto, as redes sociais podem ser definidas como: 
Sistemas de nodos e elos; uma estrutura sem fronteiras; uma comunidade não geográfica; um sistema de apoio ou um sistema físico que se pareça com uma árvore ou uma rede. A rede social, derivando deste conceito passa a representar um conjunto de participantes autônomos, unindo ideias e recursos em torno de valores e interesses compartilhados (MARTELETO, 2001, p. 72).

A partir da definição de Marteleto, podemos dizer que o conceito de rede social não diz respeito exclusivamente ao ambiente digital. Uma rede social pode existir em qualquer espaço. Em relação às mídias sociais, seu significado é complexo. Primo (2012, p. 622) reflete sobre essa complexidade da seguinte forma: "é como se mídias sociais fossem algo trivial, de significado pré-contido e transparente, um entendimento consensual e inquestionável". O autor fala que essa complexidade diz respeito às definições simplórias de que as mídias sociais representariam apenas o canal, o aplicativo ou site que pessoas utilizam para se conectar.

Em uma mídia social, é possível formar mais de uma rede social, mais possibilidades de comunicação, interação, produção de conteúdo, entre outras atividades em um único canal. Por isso, atribuiremos seu significado "guardachuva", como chama Primo (2012), de que a mídia social pode ser vista como um conjunto de meios digitais. Entretanto, o autor afirma que não se deve perder o ponto de vista analítico sobre este ambiente naturalmente digital.

As mídias sociais, como espaços de troca afetiva, existem desde a eclosão da internet em sua versão comercial. Elas começaram com e-mails e salas de Bate-papo, nas quais era possível enviar mensagens a partir de um "nickname" escolhido mediante um cadastro. Os primeiros e-mails foram enviados nos primórdios da internet, durante a década de 1970, já as primeiras salas de Bate-papo surgiram no ano de 1995 através do comunicador instantâneo "mIRC" (Internet Relay Chat). No mIRC, pela primeira vez na história, foi possível que muitas pessoas conversassem instantaneamente por um único chat (BOINEY; et al. 2008).

Com o passar do tempo e o aumento da exploração comercial da internet, outras mídias sociais surgiram, como por exemplo: o ICQ (I seek you) que inicialmente, só era permitido acessar mediante convite (OEIRAS; ROCHA, 
2001); o MSN Messenger (Microsoft Service Network), no qual era possível personalizar o perfil com uma foto da usuária/o (PEIXOTO, 2004); o Orkut, uma das mais famosas mídias sociais da primeira década deste século, foi tida como revolucionária por ampliar a possibilidade de interações como lista de amigos, comunidades e o envio dos "depoimentos" e "scraps" (RECUERO, 2004); o Fotolog, uma mídia social onde usuárias/os faziam uma espécie de diário ou álbum de fotos (RECUERO, 2006); entre outras mídias sociais como Facebook, Youtube e Twitter.

O Facebook é uma mídia social colaborativa criada em 2004, mas se popularizou no Brasil em 2007. Esta mídia social nasceu da ideia de um grupo de universitários estadunidenses que queriam conversar com universitárias do seu campus. Corrêa e Silva (2017, p. 19) definem o Facebook como "uma plataforma colaborativa na Internet que agrega diversas redes sociais, sendo capaz de alcançar muitos potenciais interessados naquilo que os perfis ali inscritos se propõem a oferecer". Devido a sua rápida popularização dentro e fora do espaço universitário, a mídia social ganhou atenção de investidores tornando-se um dos espaços mais populares para o marketing digital, influenciadores digitais, divulgação de conteúdo de outras mídias e para circulação de notícias (verdadeiras ou falsas).

O Youtube é uma mídia social criada em 2005 que permite a interação entre usuárias/os através do compartilhamento de vídeos. Os vídeos disponibilizados no Youtube podem ser reproduzidos em outras mídias sociais e para que seja possível o compartilhamento, deve-se criar uma conta na mídia. A popularidade entre usuárias/os se dá a partir de inscrições no canal e nas interações "like" e "dislike" ("curtir" e "não curtir"). Esta mídia é considerada uma das mais promissoras para o mundo do trabalho no século XXI; surgiu nela, por exemplo, uma nova forma de trabalho e uma nova profissão: as/os “youtubers" (SANTOS; SILVA; ZATTAR, 2016).

O Twitter é uma mídia social criada em 2006 com o objetivo de compartilhar mensagens curtas e objetivas, incentivando que usuárias/os compartilhem de forma rápida "a essência da ideia que estão tentando comunicar" (SOUSA; SILVA, 2016, p. 30). Essas mensagens curtas são 
chamadas de "tweets" e nelas podem ser adicionadas fotos, textos de até 140 caracteres e/ou links para vídeos, notícias e outras mídias. Foi no Twitter que nasceram as hashtags indexando palavras, ideias ou expressões por suas/seus usuárias/os. Possivelmente, por conta da velocidade e volume das postagens dessa rede social, as hashtags acabaram por se tornar uma ferramenta útil para recuperar informação em meio a uma "correnteza" de informações tão heterogênea e acelerada. As hashtags mais utilizadas entram no ranking de popularidade conhecido como "trending topics". Neles aparecem os assuntos mais compartilhados e comentados em um espaço curto de tempo (assuntos do momento). Esses assuntos podem ser sobre diversos temas, tais como: política, esportes, tecnologia, ativismo digital, entre outros.

Entre tantas outras mídias sociais que não exploramos aqui, o fato é que seu uso tem modificado as formas de comunicação entre as pessoas e, portanto, suas formas de afeto. Algo já vislumbrado décadas antes do surgimento dessas redes por Vilém Flusser (2010, 2017), que afirmava ser as formas de escrita digital meios de registro não mais produzidas e acessíveis diretamente pelo humano, mas somente possíveis a partir da mediação de um apparatus (aparelho) capaz de mediar, sintetizar, traduzir, bits e códigos binários em uma forma de comunicação linguística inteligível pelo humano.

Assim como a revista, o cinema e a TV influenciaram gerações, acreditamos que as novas mídias e atoras/es que nelas agem e interagem, também influenciam e são influenciados por outras pessoas que utilizam esses espaços. Isso pode representar um cenário interessante pois possibilita a expressão de sentimentos e formação de redes afetivas e comerciais diversas, ainda que possa trazer danos para seus usuários, tais como: a perda de referência entre o campo do real e o campo do virtual, hiperexposição, julgamento moral, compartilhamento de discursos de ódio, transtorno de ansiedade, vigilância indevida, entre outros problemas. Antunes e Matheus (2019, p. 248) corroboram salientando que "uma das características da mídia contemporânea é que ela é altamente emotiva" e, por isso, podem acarretar tantos danos para suas usuárias/os. 
Quando trazemos essa perspectiva relacionada aos estudos de gênero, buscamos convergir as reflexões de teóricas/os destes estudos com a característica apresentada. Sendo assim, somamos à observação deste fenômeno as reflexões sobre a condição da mulher e idealização das relações afetivas apontadas por Michel Foucault (1985), Júlia Kristeva (1989), Helleieth Saffioti (2002), Simone de Beauvoir (2014) e Angela Davis (2016). E das reflexões sobre a masculinidade algoz de si e de demais gêneros - portanto tóxica, grosso modo - identificadas na percepção de Pierre Bourdieu (2010) e mesmo nas contribuições de Judith Butler (2003) a respeito da performatividade masculina e feminina, assim como sobre a heterossexualidade compulsória; e de Fani Hisgail (2007), o que tange à relação com a pedofilia.

Retomando à web 2.0, ressaltamos sua importância para analisar os novos fenômenos ocorridos nesta nova Internet. Diferente de sua antecessora, esta nova versão da web avançou em outras linguagens de programação além da HTML, como por exemplo a PHP, JavaScript, Python, entre outras linguagens. Isso possibilitou uma maior variedade de usos e criação de negócios no ambiente digital. No que diz respeito a organização do conhecimento, esta nova web abriu espaço para diferentes serviços, chegando finalmente a conhecida web 3.0 onde o advento do ferramental semântico não só permitiria melhor mapeamento e recuperação dos conteúdos outrora indexados e classificados por exemplo, no armazenamento de informação em ambiente digital, conhecido popularmente como armazenamento em nuvem -, como a disseminação de resultados de pesquisas e, portanto, informações. Sendo elas verdadeiras ou fakes - no ambiente das redes sociais que veriam surgir mais e mais "bolhas" de influência, referentes às amizades e aos seguidores que, agora com a web semântica, estruturar-se-iam mais rapidamente.

Estas últimas mudanças não apenas alargaram o escopo de dados e informações que poderiam ser recuperados como auxiliou o desenvolvimento de um novo campo sociotécnico já não restrito às práticas ou ambientes de trabalho e meios de produção, mas que se estendia às práticas cotidianas públicas e privadas. É nessa última que violências outrora abafadas pelas paredes das 
residências e postos de trabalho, se tornavam visíveis a partir da frágil segurança que as mídias sociais ofereciam aos seus protagonistas.

No caso do Facebook, os algoritmos ou "filtros bolha" não só estão presentes nas sugestões de amizades, páginas e grupos como também influenciam nas buscas realizadas no campo "pesquisar" desta mídia social. Se uma pessoa interage ativamente no seu perfil e possui em sua rede uma quantidade maior de pessoas que partilham do seu posicionamento político/ ideológico, provavelmente esta pessoa verá em sua "timeline" mais conteúdos que estão de acordo com suas opiniões do que o contrário. Sendo assim, se uma pessoa posta alguma opinião sobre determinado assunto e usa uma hashtag para torná-lo visível, curte páginas que focam nesses conteúdos e interage com esse tipo de publicação, ela pode consumir mais informações direcionadas a ela sobre o mesmo assunto.

É importante ressaltar aqui, antes da próxima seção que tratará de maneira mais pormenorizada da temática da violência contra as mulheres já se utilizando de material coletado das mídias sociais investigadas, que a raspagem de registros nessas mídias sociais pode apresentar resultados diferentes de acordo com as ferramentas empregadas. A variedade de ferramentas e a plasticidade das abordagens feitas ao definir o que buscar nas mídias e a partir de quais critérios, juntamente com questões de ordem humanísticas em torno dos aspectos e categorias de análise que versem sobre violência, sexualidade, gênero, privacidade, entre outras, extrapolam fronteiras da CI. E é a partir dessa percepção que entendemos que o que foi ora produzido, fruto de uma dissertação de mestrado em CI (ROMEIRO, 2019), marcada pela sua abordagem interdisciplinar, precisa ser confrontado com o olhar das práticas vigentes nas HD.

O uso das hashtags como parâmetro para localizar as informações nessas respectivas mídias pode e deve ser visto como método presente na CI, mas a discussão advinda dessa coleta não se encerra nela própria. Ela supre, pela riqueza de seu conteúdo, debates egressos das humanidades lato sensu e guardam um potencial de análise rico no caso de haver reuso desses mesmos dados de pesquisa, seja por meio de outra ferramenta digital que possibilite o 
processamento de outros resultados, outras formas de ver os dados, seja pelo ato de outras questões serem postas a tais dados então coletados.

Há ganhos essenciais e insubstituíveis a serem obtidos com a aplicação de ferramentas digitais ao projeto de interpretar (e reinterpretar) o registro humano para a edificação da sociedade. Para um número desconcertantemente grande de outsiders, as humanidades digitais qua humanidades continuam interessantes, porém irrelevantes. Anthony Grafton fala pela maioria quando, num artigo recente do New York Times (Cohen), ele repete a plausibilidade de que as humanidades digitais são um meio e não um fim. (ALVARADO, 2012). ${ }^{4}$

Aproveitamos o ensejo encontrado no registro de Rafael Alvarado para ressaltar que práticas metodológicas que tratem de forma inovadora os determinados registros sociais por meio das TIC, e que versem sobre questões políticas, culturais, socioeconômicas e, portanto, de fundo humanístico, quando realizadas entre as fronteiras da CI, podem ser consideradas parte constitutiva da comunidade de práticas que representam as Humanidades Digitais. Novamente, menos como um fim, mas considerando-as como meio passível de serem usadas e reproduzidas em um campo com tantas similaridades, conforme apontamos anteriormente, nosso intento é aproximar da pesquisa realizada seu potencial contribuição para pensarmos abordagens cada vez mais familiares às HD que convirjam para a produção científica da CI.

\section{A violência contra mulheres desvelada pelas hashtags}

Demonstraremos com um exemplo pessoal a limitação de conteúdos devido à programação de algoritmos ou "filtros bolha": o perfil da primeira autora deste artigo, referente à mídia social Facebook, encontra-se ativo desde 2007. Vale apontar que sua interação e quantidade de amigos nesta rede modificou bastante a medida em que uma série de dinâmicas e experiências singulares passaram a ser registradas naquele perfil ao longo dos anos. Enquanto mulher, lésbica, feminista, a autora sinaliza e reconhece que grande parte do conteúdo que aparece em sua timeline flerta com interesses e críticas pessoais. 
O ativismo em oposição a violência contra mulheres nas mídias sociais se iniciou no ano de 2015. O ano ficou popularmente conhecido como o ano do empoderamento da mulher nas mídias sociais. O uso desses espaços como espaços de militância para pautas das mulheres e feminismo se popularizou a partir da cerimônia do Oscar de 2015. Nesse evento, diversas participantes utilizaram a hashtag \#AskHerMore (pergunte mais a ela) para combater estereótipos de gênero e misoginia por parte de jornalistas, ao perguntar mais sobre a vestimenta de mulheres do que sobre seus trabalhos. (COSTA; BARBA; IDOETA, 2015).

No Brasil, o uso de hashtags para ativismo em oposição a violência contra mulheres também começou no ano de 2015 e continua até os dias atuais. A primeira Hashtag a se popularizar no país foi a \#primeiroassédio, incentivada também no Twitter pela ONG "Think Olga", ao denunciar atos pedófilos de homens em relação a uma menina de 12 anos participante do programa de culinária "Masterchef Júnior". A partir da denúncia, diversas mulheres e homens compartilharam seus primeiros assédios sofridos, deixando a temática da naturalização do assédio no Twitter e Facebook em evidência até os dias atuais. Silva (2018) aponta que a aderência do movimento foi tamanha que esta hashtag foi utilizada mais de 82 mil vezes em menos de uma semana.

A partir desta emergiram outras hashtags, sempre associadas a acontecimentos noticiados em diversos canais de comunicação, como por exemplo: a \#nãomereçoserestuprada após a divulgação do resultado de uma pesquisa que mostrava o fato de a culpa pelo estupro estar associada à roupa das vítimas; a \#mexeucomumamexeucomtodas, que surgiu após a denúncia de assédio sexual de no blog \#Agoraéquesãoelas, na qual um ator era denunciado por uma figurinista, ambos funcionários de uma emissora de televisão aberta; a \#amigosecreto emergiu para denunciar as violências sexuais sofridas por mulheres com algozes que um dia foram considerados seus amigos; a \#deixaelatrabalhar foi utilizada para denunciar o assédio contra mulheres jornalistas esportivas no seu exercício profissional; a \#aconteceunocarnaval surgiu para denunciar os casos de assédio e estupro no carnaval de 2018; entre outras (SILVA, 2018). 
Apesar de as mídias sociais representarem um certo risco a privacidade e limitar o acesso a conteúdos mais variados, elas também podem ser vistas como aliadas em algumas situações, como, por exemplo, na visibilidade de assuntos a partir da indexação (etiquetagem) popular. Nesse sentido, a folksonomia das hashtags nas mídias sociais representam novas estratégias de militância e exposição de temáticas como a desnaturalização da violência sexual contra mulheres na sociedade, o combate ao racismo, denúncias de corrupção, etc. A seguir, serão apresentados os resultados desta pesquisa que consiste na avaliação das hashtags \#primeiroassédio e \#mexeucomumamexeucomtodas na mídia social Facebook.

\subsection{Da aplicabilidade das hashtags no combate à violência contra a mulher: primeiros resultados e procedimentos metodológicos}

Como exposto no início dessa comunicação, um dos objetivos desta pesquisa é mapear e analisar as hashtags \#primeiroassedio e \#mexeucomummexeucomtodas na mídia social Facebook a fim de mediar as reflexões sobre HD e CI e gênero em relação ao fenômeno das hashtags. Apesar de ambas as hashtags terem nascido na mídia social Twitter, optamos pelo Facebook, pois buscamos analisar com profundidade os relatos e denúncias encontrados. Sendo assim, a limitação de caracteres permitida nas postagens do Twitter (140 caracteres) não nos traria o mesmo detalhamento das narrativas que os dados mapeados no Facebook.

A coleta dos dados foi realizada no Facebook no período de 18 de dezembro de 2018 a 28 de janeiro de 2019. Para que a pesquisa não fosse influenciada por uma conta já existente, entendendo aí a possível interferência das bolhas e filtros, foi criada uma nova conta de e-mail sem discriminação de gênero com o nome. A partir deste e-mail, foi criada uma conta no Facebook com o nome fantasia Ariel, uma vez que acreditamos que este nome não seja direcionado a nenhum gênero especificamente. Este perfil fantasia não realizou nenhum tipo de interação: nenhum amigo, nenhuma página curtida e nenhuma postagem. 
Como já exposto, o mapeamento dos dados foi realizado através do campo "pesquisar" com filtros específicos. Dentro dessas condições, foram mapeadas o total de 1.035 postagens. Justificamos esse resultado quantitativo por se tratar de uma conta nova e sem interações, logo, possibilidades reduzidas dos algoritmos trazerem maiores resultados.

Escolhemos coletar os dados a partir das hashtags \#primeiroassedio e \#meuprimeiroassedio pois observamos que apareciam postagens com uma delas ou com as duas juntas. Para que não houvesse problemas em relação à coleta, utilizamos as hashtags com os mesmos termos utilizados na mídia social Twitter, espaço em que os movimentos nasceram. Cabe ressaltar que ao colocar os termos na aba "pesquisar", não utilizamos acentuação, pois poderia haver usos das hashtags com ou sem acento. Assim, pôde-se coletar todas as publicações, com ou sem acentuação.

Para organizar as informações coletadas, utilizamos o software Excel onde geramos uma planilha e os gráficos. Na planilha, organizamos as informações referentes aos tipos de postagem de acordo com as categorias: "fotos", "vídeo", "relato", "notícias" e "outros". Adotamos o uso da categoria "outros" pois como nos mostrou Souza (2007), os sistemas de organização do conhecimento não são perfeitos. Sendo assim, podem existir nos próprios sistemas uma classe ou categoria para generalidades que não se enquadram em nenhuma das outras classes, como por exemplo a classe 000 da Classificação Decimal de Dewey intitulada "generalidades"; e a classe zero (0) da Classificação Decimal Universal também intitulada "generalidades".

Na tabela do Excel, além da categorização, também foram observados outros fatores para a pesquisa, tais como: a quantidade de curtidas, comentários, compartilhamentos, visualizações e gênero da pessoa que postou, homem ou mulher (aqui não foi possível identificar o gênero de acordo com o que a pessoa se reconhece, classificamos conforme a pessoa é lida na sociedade, como homem ou mulher).

De acordo com o número total de postagens pesquisadas, notamos que as "fotos" foi a categoria que mais teve postagens, representou cerca de $50 \%$ dos dados coletados. A segunda categoria que mais apareceu foi "relatos", com 
cerca de 19\%. Em terceiro lugar, "vídeos", com cerca de 18\%. A categoria "notícias" representou cerca de $12 \%$ e, por fim, a categoria "outros", com aproximadamente $1 \%$.

Acreditamos que os resultados foram maiores para a categoria "fotos" porque a pesquisa foi realizada em um perfil sem interações, diante disso, não foram gerados algoritmos que sincronizassem com textos postados pelo perfil Ariel. Uma outra análise possível está ligada ao fato de que apesar da popularização das hashtags, do apoio à causa, muitas pessoas, especialmente mulheres, não se sentem confortáveis em relatar suas vivências em uma mídia social no modo de publicação público (acreditamos que muitos relatos foram postados apenas para a rede particular de amigos das pessoas).

\section{Análise dos dados da \#primeiroassedio e \#meuprimeiroassédio}

A hashtag \#primeiroassédio surgiu em outubro de 2015 impulsionada pela ONG "Think Olga", quando uma participante do programa "Masterchef Júnior" foi assediada por diversos homens na mídia social Twitter. Esses tweets com assédio direcionado à jovem incitavam violência sexual, e por ela ser menor de 18 anos, esse tipo de incitação é caracterizado legalmente como ato pedófilo (ver figura 2). O comportamento desses usuários do Twitter são um exemplo de problemas sociais encontrados na estrutura patriarcal.

Figura 1 - Assediadores no Twitter

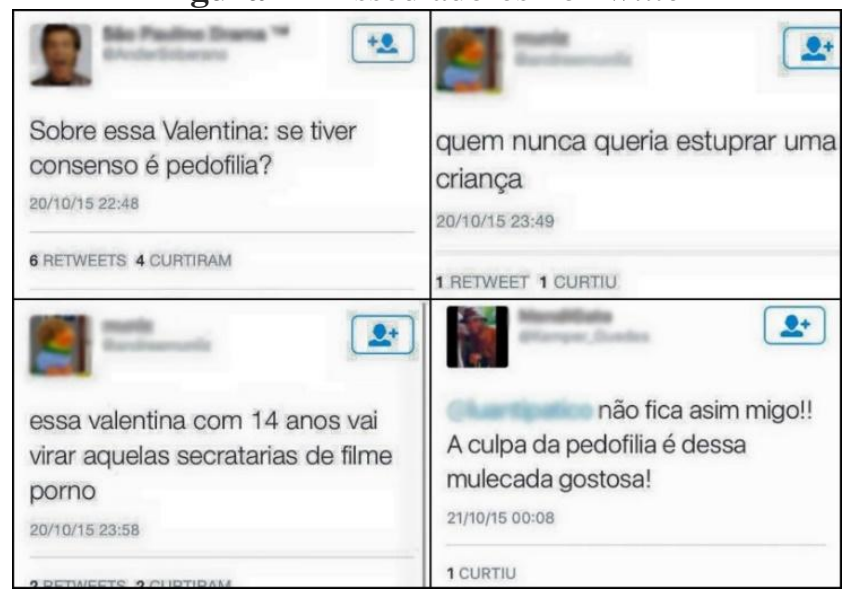

Fonte: Hueck (2015). 
Os exemplos expostos na figura 2 mostram o quanto a cultura do estupro ainda está presente na sociedade. O primeiro tweet encontrado na figura está relacionado a cultura do estupro, na medida que se "romantiza" o consenso, diminuindo assim o crime de uma pessoa adulta se relacionar sexualmente com uma criança, conforme consta no código penal brasileiro (BRASIL, 1940). O segundo tweet naturaliza a violência sexual contra crianças e adolescentes, o que Hisgail (2007) caracterizou como ato pedófilo. O terceiro objetifica o corpo da menina para exploração sexual, um crime que também consta no código penal. O quarto culpabiliza a vítima, comportamento característico da cultura do estupro (FOUCAULT, 1985; BEAUVOIR, 2014).

Essas postagens causaram revolta de diversas mulheres e homens, e foram comentadas, em diversas mídias sociais. Com base nessa repercussão, a ONG Think Olga lançou a campanha \#primeiroassedio. Esta campanha tinha o objetivo de expor a naturalização da violência sexual na infância, tratando-a como um problema social e apoiando mulheres no entendimento de que a culpa não é da vítima. Foi quando diversas mulheres se encorajam a contar os primeiros assédios sexuais que sofreram durante a infância e a adolescência.

Na mesma semana em que a campanha foi lançada no Twitter, surgiram postagens com relatos sobre o primeiro assédio também no Facebook. As postagens do Facebook, portanto, eram mais detalhadas, especialmente porque nesta mídia social não há uma restrição de 140 caracteres por postagem como ocorre no Twitter. Assim, de acordo com as condições detalhadas nos procedimentos metodológicos, foram mapeadas 611 postagens sobre a \#primeiroassedio e \#meuprimeiroassedio.

Assim como visto anteriormente, a categoria que mais teve postagens foi "fotos", representando 53\% das postagens. A categoria "relatos" contou com aproximadamente 18\%. As "notícias" representaram 14\%. A categoria "vídeos" teve $13 \%$ dos resultados. Por fim, a categoria "outros" contou com $4 \%$ das postagens.

Dessas postagens, identificamos que $46 \%$ foram realizadas por grupos ativistas, empresas ou partidos políticos. Parte delas eram compartilhamentos de postagens do Twitter, denúncia de casos de violência contra mulheres e 
compartilhamento de campanhas contra a violência sexual. As mulheres foram responsáveis por $44 \%$ das postagens. Nestas, encontramos diversos relatos de assédios e/ou estupros sofridos por mulheres durante a infância e adolescência, além de mensagens de apoio a quem estava conseguindo postar suas vivências. Os homens realizaram $10 \%$ das postagens mapeadas. Nestas, encontramos mensagens de apoio às mulheres, relatos de primeiros assédios cometidos por homens e mensagens contra o movimento, em repúdio à campanha.

Abaixo, serão apresentados exemplos de conteúdos que fizeram parte desse levantamento. Não trataremos de todas as categorias simplesmente por motivo de adequação ao modelo deste artigo pois, em caso contrário, nos estenderíamos demasiadamente. Ressaltamos que a categoria nomeada "fotos" engloba todo conteúdo que utilizou recursos imagéticos (fotografias, pôsteres, charges, ilustrações, prints, etc.).

Em uma imagem postada e indexada com a \#primeiroassédio, foi feita uma colagem com postagens de homens que iam contra o movimento no Twitter. Nesses posts, tinham mensagens como "A mina é feia e tá contando experiência na tag \#primeiroassedio. Ngm acredita quirida", "a maioria de vocês não teria sofrido assédio se não andassem como vadias", "ala o campeonato de quem foi mais molestada", e "estou me masturbando lendo todos os relatos, por favor continuem".

A postagem que denunciou esse tipo de comportamento dos homens contou com 466 curtidas, 39 comentários e 234 compartilhamentos. Esses dados mostram que esse tipo de postagem que denunciou atitudes machistas e preconceituosas foi discutida e compartilhada, ampliando assim a discussão sobre o tema.

$\mathrm{Na}$ categoria "relatos" pudemos observar determinados padrões de ocorrência, como o fato de a maioria das experiências terem ocorrido antes dos 12 anos de idade, por pessoas próximas às vítimas. Outro fator também identificado é que $70 \%$ dos relatos foram realizados por mulheres que disseram nunca terem conseguido esquecer os traumas. Também tiveram relatos de homens apoiando o movimento, alguns contaram os primeiros assédios que 
cometeram e outros problematizaram a masculinidade tóxica, como veremos na figura 6.

Figura 2 - Categoria relatos: Homem apoiando o ativismo das mulheres

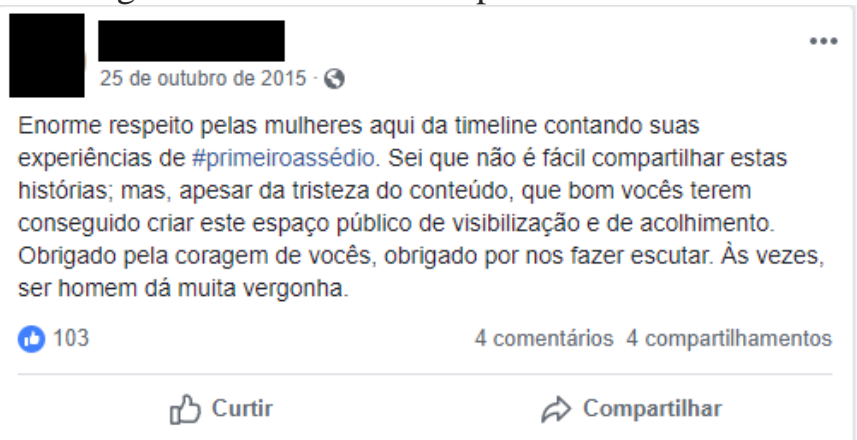

Fonte: Dados da pesquisa.

Na figura acima, podemos observar que homens também demonstraram seu apoio ao movimento e consideraram o assédio um problema social que deve ser visibilizado e acolhido pela sociedade. Ressaltamos que a estrutura patriarcal e o machismo também afetam os homens, especialmente na perspectiva de que homens devem ser fortes, viris e heterossexuais (BUTLER, 2003).

$\mathrm{Na}$ categoria "notícias" foi observado um grande número de compartilhamentos no que diz respeito às interações. Em média, cada notícia mapeada nesta pesquisa foi compartilhada 467 vezes. Essas notícias compartilhadas vieram de canais de comunicação diversos, todos fora da mídia social Facebook. Dentre os assuntos noticiados mais encontrados, destacamos: matérias sobre a popularização do movimento \#primeiroassedio, problematização da violência contra meninas e mulheres, denúncias sobre feminicídio e notícias sobre homens fazendo mea culpa.

Uma notícia divulgada no site Uol Notícias dizia respeito a denúncias que ocorreram no Facebook após a popularização da \#primeiroassedio. Nesta notícia, diversas estudantes de várias cidades brasileiras relataram os assédios sofridos nas escolas por professores e demais funcionários das instituições. Essa informação mostra o quanto a popularização de uma hashtag pode servir de empoderamento para denúncia de assédios em diversas instituições, inclusive nas escolas, espaço em que estudantes devem estar seguros como previsto no Estatuto da Criança e do Adolescente - ECA (BRASIL, 1990). 
Encontramos também uma notícia relacionada à popularização do movimento puxado pela ONG Thing Olga. Entretanto, a mesma foca em contar os casos de homens que reconheceram os assédios cometidos e refletiram sobre o machismo e a importância do feminismo. Reforçamos que matérias como essa, divulgadas por um canal de comunicação popular ( $O$ Globo), dentro e fora das mídias sociais, é importante para que esse tipo de debate ganhe mais espaço na sociedade entre todos os gêneros.

Em relação a periodicidade das postagens, notamos que apesar de o boom ter acontecido em 2015, a hashtag continuou sendo utilizada nos anos posteriores. Encontramos postagens até dezembro de 2018, como exposto na Figura 3.

Gráfico 1 - Cronologia das postagens \#primeiroassedio e \#meuprimeiroassedio

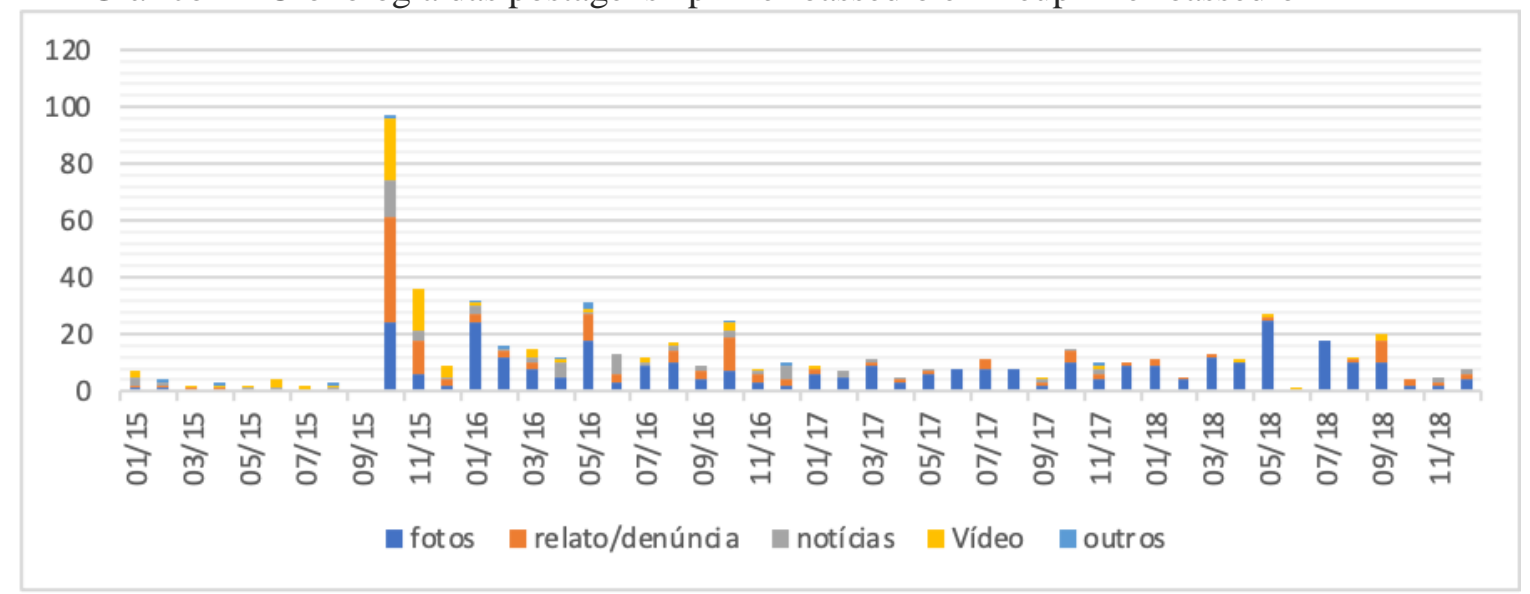

Fonte: Dados da pesquisa.

Na figura acima podemos notar que o período de maior concentração de postagens foi entre setembro e novembro de 2015, período de duração do programa Masterchef Júnior. Este, portanto, foi o período de maior concentração de relatos. A maior quantidade de vídeos também foi postada neste período. Na categoria fotos, encontramos postagens mais espalhadas, desde o boom até dezembro de 2018. As notícias também têm sua frequência espalhada, aparecem no boom, mantém uma linearidade em 2016, têm pouca incidência em 2017 e retorna no final de 2018, especialmente associado a denúncia de um líder espiritual que abusou sexualmente de mais de 200 mulheres. 
Através dos dados expostos, notamos que o assédio sexual na infância e adolescência expõem uma relação de poder e dominação de homens em relação às mulheres, mas também observamos o ativismo no sentido de expor $\mathrm{o}$ problema para levantar a discussão na sociedade e, assim, minimizar a quantidade de assédios e abusos sexuais na infância. Cabe lembrar que não é só na infância que ocorrem os assédios, estes podem acontecer em diversos momentos na vida das pessoas (principalmente mulheres) como poderemos ver através da avaliação da \#mexeucomumamexeucomtodas.

\section{Análise dos dados da \#mexeucomumamexeucomtodas}

O movimento \#mexeucomumamexeucomtodas emergiu no ano de 2017 a partir de dois casos. O primeiro refere-se à denúncia do assédio sexual no ambiente de trabalho na qual uma figurinista denunciou um ator de uma rede de televisão aberta no quadro \#AgoraÉQueSãoElas do jornal Folha de São Paulo (2017). Feita a denúncia, a figurinista ganhou apoio de diversas colegas de trabalho para que o assunto fosse amplamente discutido nas mídias sociais. Assim surgiu no Twitter a \#mexeucomumamexeucomtodas. Poucos dias depois, ocorreu o segundo caso que contribuiu para a ascensão do movimento: um participante de um reality show desta mesma emissora foi expulso por agredir sua namorada que também participava do programa (ROMEIRO; SILVA, 2018).

A partir destes acontecimentos, ocorreram discussões nas mídias sociais Twitter e Facebook. Essas discussões, indexadas a partir do uso da hashtag levantaram temáticas como assédio sexual no ambiente de trabalho, relacionamentos amorosos abusivos, empoderamento feminino e sororidade entre as mulheres. Com base nisto, analisamos as publicações que utilizaram as hashtags na mídia social Facebook, de acordo com as categorias mencionadas.

A maioria das postagens mapeadas neste estudo foram "fotos", representando $45 \%$ das postagens. A segunda categoria mais postada foram os "vídeos", com 25\%. Em terceiro lugar ficaram os "relatos", representando 14\%. $\mathrm{Na}$ quarta posição ficaram as "notícias", que correspondem a 6\%. Por fim, a categoria "outros", com $10 \%$ dos resultados. 
Destacamos que nesta hashtag a maior quantidade de postagens foi realizada por mulheres (cerca de 60\%). Em segundo lugar, vieram as postagens dos grupos, pessoa jurídica e partidos políticos que tiveram o total de $28 \%$ dos resultados. Por fim, as postagens realizadas por homens tiveram a menor expressão, representando $12 \%$ das publicações mapeadas.

A maioria das postagens, referiam-se às mulheres e sobre a importância de sua respectiva união em oposição a violência. Coincidentemente, a maioria era fotos de mulheres e sua rede de apoio e relatos de violências sofridas em relacionamentos abusivos, passeatas, assédio sexual no ambiente de trabalho e em outros espaços. As postagens realizadas por pessoas jurídicas, grupos e partidos políticos fixaram no compartilhamento de conteúdos informativos sobre violência contra a mulher, charges, ilustrações e outras mensagens sobre empoderamento das mulheres.

As postagens de homens, por sua vez, estiveram majoritariamente tecendo críticas ao movimento. Muitos desqualificaram o movimento e a atitude das colegas de trabalho da figurinista, questionaram, inclusive, se a sororidade se estendia a pessoas que não pertencesse àquela classe social. A seguir, serão apresentados alguns exemplos de postagens selecionadas nas categorias informadas.

Na figura 3, podemos observar a importância deste movimento para denúncia e reflexão sobre pedofilia no Brasil. A imagem mostra uma denúncia a um participante de um reality show brasileiro que se relacionava com mulheres mais jovens (conhecidas como "novinhas"). O denunciado também confessou que recorria a bebidas alcóolicas para "facilitar as coisas" ou seja, para que a vítima ficasse mais vulnerável às investidas. Ressaltamos que, de acordo com o ECA (BRASIL, 1990) e com o Código Penal Brasileiro (BRASIL, 1940) oferecer bebida alcóolica e seduzir crianças e adolescentes é crime, portanto, estas atitudes devem cada vez mais serem desnaturalizadas do imaginário e comportamento social.

Na categoria "relatos", foi possível observar o repúdio à naturalização da violência contra mulheres. Também haviam relatos que expunham a indignação em relação ao ativismo ter mais visibilidade quando realizado por mulheres de 
classe social abastada. Na figura 15, pode ser notada uma problematização relacionada ao corpo da mulher, especialmente no respeito que elas merecem ao frequentar o espaço que quiserem.

Figura 3 - Categoria relatos: o corpo da mulher

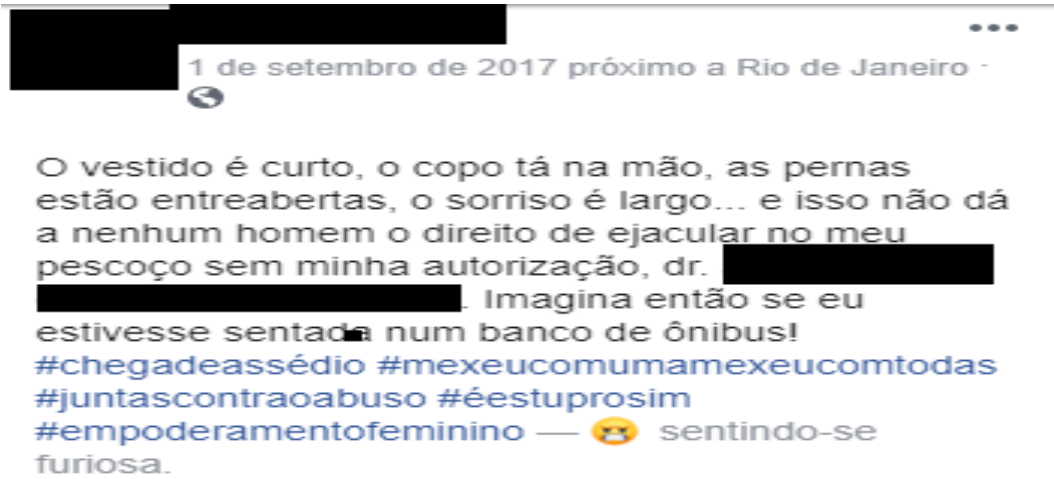

(b) $=65 \quad 21$ comentários 6 compartilhamentos

Fonte: Dados da pesquisa.

Podemos relacionar o conteúdo desta postagem à discussão sobre o “corpo objeto" abordado por Júlia Kristeva (1989). Essa publicação referia-se especificamente a um caso noticiado na época sobre um homem ter se masturbado no transporte público e ejaculado no pescoço de uma mulher no Rio de Janeiro. A indignação relatada na postagem refere-se ao juiz que julgou o caso e não aplicou as medidas cabíveis ao acusado.

Quanto às "notícias", a maioria delas referia-se ao caso da figurinista, entretanto, em dezembro de 2018, também foram encontradas postagens sobre o caso do líder espiritual abusador $(\mathrm{G} 1,2018)$. Destacamos também uma que teve bastante repercussão, a notícia de que uma mulher que esteve em coma por anos foi violentada, engravidou, e deu à luz ainda desacordada (G1, 2019). Este caso aconteceu nos Estados Unidos e, a partir dele, pudemos notar que abusos sexuais têm relação com poder e abjeção, especialmente porque a vítima não tinha nenhuma condição de consentir nem se defender (KRISTEVA, 1989).

Em relação a categoria "vídeos", estes também expuseram alguns relatos, campanha contra a violência sexual ou manifestações artísticas para 
empoderamento de mulheres. Esta categoria normalmente é que possui mais interações (curtidas, comentários, compartilhamentos e visualizações). Para esta hashtag, identificamos uma média de 3.700 visualizações por conteúdo.

Figura 4 - Cronologia das postagens \#mexeucomumamexeucomtodas

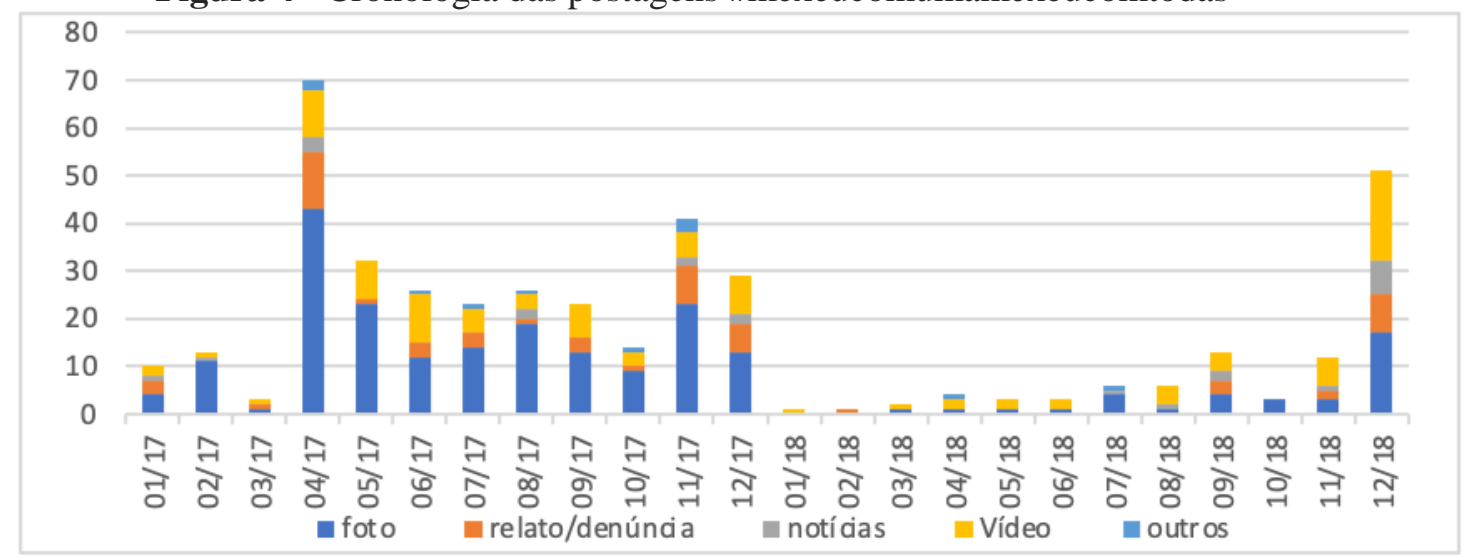

Fonte: Dados da pesquisa.

Como podemos observar no gráfico, a maior concentração de postagens aconteceu no mês de abril de 2017, período em que surgiram as notícias sobre o assédio vivido pela figurinista. Notamos que a hashtag manteve uma média de uso entre 20 e 40 postagens durante todo o ano de 2017. A categoria mais postada foi "fotos", entretanto, em dezembro de 2018, devido aos acontecimentos discutidos acima, a maior categoria postada passou a ser "notícias".

A partir desse gráfico, podemos notar que quando ocorre um caso de violência contra mulher e ele repercute nas mídias, principalmente quando televisionado, é indexado pelas pessoas através das hashtags. Assim como a \#primeiroassedio, a \#mexeucomumamexeucomtodas ficou tão presente no imaginário das pessoas que até o final de 2018 ainda era possível encontrar conteúdo classificado com essa hashtag. Com isso, reforçamos a importância desses movimentos para o ativismo nas mídias sociais, principalmente porque eles podem expressar problemas enfrentados por mulheres, fortalecimento de redes de apoio, empoderamento e desconstrução sobre a naturalização da violência, seja ela física, sexual ou psicológica. 
Reforçamos que estes dados não representam o total do que foi publicado nestas mídias sociais, sobretudo porque não conseguiríamos mapear o total de usos devido à personalização de serviços dessas empresas através dos algoritmos que formam os "filtros bolha" (PARISER, 2010; BEZERRA, 2017). Assim, observamos como o assunto apareceu para um perfil sem interações, portanto, sem muitas possibilidades de cruzamento de dados por semelhança de interações.

\section{Considerações finais}

As mídias sociais aqui representadas são espaços sociais catalizadores do melhor e do pior das práticas sociais interacionais humanas. Não são apenas espaços de simulação do real, mas atuam com verdadeiros simulacros desse real, interferindo nele e contribuindo direta e indiretamente para sua transformação. No contexto da violência contra a mulher, percebemos que o canal eletrônico, a partir da potência digital dos registros infocomunicacionais ali identificados e coletados para esta pesquisa, espelha em grande medida uma imagem de uma sociedade ainda detentora de inúmeras formas de violência naturalizadas, banalizadas no dia a dia de parte significativa da população. A "ágora" eletrônica possibilita que vozes recalcadas por convenções sociais possam ser produzidas e registradas em aparentes espaços "opacos".

Sabemos que se os algoritmos não são "neutros", tampouco as mediações via plataformas digitais os são. Contudo, não podemos nos esquecer que os indivíduos que registram suas opiniões, seus posicionamentos, seus desejos e fetiches nessas mesmas plataformas, devem ter responsabilidade em seus atos. Ou seja, muitos responsáveis por tais violências acreditam que não serão responsabilizados ou encontrados. A luta é grande, mas há indícios de que a responsabilização criminal desses sujeitos sociais é possível e crescente. Contudo, muito há de se realizar para que tais violências não se mantenham banalizadas. Como dissemos, algoritmos, plataformas e indivíduos não são neutros. Ninguém o é.

Este artigo buscou apontar para tal perspectiva e traz consigo uma forma relatada de como cientistas da informação podem trabalhar em sua perspectiva 
informacional, com pesquisas onde o objeto e o problema que o impacta não são originariamente do campo disciplinar da CI. Essa aproximação, portanto, nos convida a pensar uma articulação com as Humanidades Digitais. Afinal, é nessa articulação que se percebem questões e abordagens características das ciências humanas, sociais e sociais aplicadas - portanto, humanidades - sendo repensadas e reelaboradas com base nas competências informacionais e computacionais.

No caso da violência contra as mulheres, das diversas formas de discriminação ali implícitas, as HD podem fundamentar uma metodologia e sustentá-la por meio dos recursos computacionais aplicados à indagações de fundo humanístico, ampliando a nossa capacidade de compreensão a respeito de tais absurdos que a sociedade reproduz, agora mediados pelas tecnologias de informação e comunicação.

\section{Agradecimentos (financiamento)}

Ao Programa de Pós-graduação em Ciência da Informação (PPGCI/IBICTUFRJ). Ao Programa de Pós-graduação em Ciência da Informação (PPGCI/UFMG). Coordenação de Aperfeiçoamento de Pessoal de Nível Superior (CAPES), ao Conselho Nacional de Desenvolvimento Científico e Tecnológico (CNPQ) e à Fundação de Amparo à Pesquisa do Estado do Rio de Janeiro (FAPERJ).

\section{Referências}

ALVARADO, Rafael C. The Digital Humanities Situation. In: GOLD, Matthew K. (ed.). Debates in Digital Humanities. Minneapolis: University of Minnesota Press, 2012.

ANTUNES, Bianca Fernandes; MATHEUS, Leticia Cantarela. Cartografia da violência no Facebook e a experiência do medo The cartography of violence on Facebook and the experience of fear. INTERIN, [Paraná], v. 24, n. 1, p. 242$261,2019$.

BAYLEY, Moya Z. All the Digital Humanists Are White, All the Nerds Are Men, but Some of Us Are Brave. Journal of Digital Humanities, [S.l.], v.1, n. $1,2011$. 
BEAUVOIR, Simone de. O segundo sexo. Rio de Janeiro: Nova Fronteira, 2014.

BEZERRA, Arthur Coelho. Vigilância e cultura algorítmica no novo regime de mediação da informação. Perspectivas em Ciência da Informação, Belo Horizonte, v. 22, n. 4, 2017.

BOINEY, Lindsley G. et al. Taming multiple chat room collaboration: Realtime visual cues to social networks and emerging threads. In: Proceedings of the Fifth International ISCRAM Conference, 5, 2008, Washington, DC: ISCRAM, 2008. p. 660-668.

BOURDIEU, Pierre. A dominação masculina. Rio de janeiro: Bertrand Brasil, 2010.

BRASIL. Lei n ${ }^{\circ}$ 2.848, de 7 de dezembro de 1940. Código Penal. Diário Oficial [da] União, Rio de Janeiro, 31 dez. 1904. Retificado em 31 jan. 1941.

Disponível em: http://www.planalto.gov.br/ccivil_03/decreto-lei/Del2848.htm. Acesso em: 16 fev. 2019.

BRASIL. Lei n ${ }^{\circ}$ 8.069, de 13 de julho de 1990. Dispõe sobre o Estatuto da Criança e do Adolescente e dá outras providências. Diário Oficial [da] União, Brasília, DF, 1990. Disponível em: http://www.planalto.gov.br/ccivil_03/Leis/18069.htm. Acesso em: 20 jan. 2019.

BUTLER, Judith. Problemas de gênero: feminismo e subversão da identidade. Rio de Janeiro: Editora Record, 2003.

CORRÊA, Elisa Cristina Delfini; SILVA, Franciéle Carneiro Garcês da. Presença digital dos Conselhos Regionais de Biblioteconomia do Brasil no Facebook. Perspectivas em Ciência da Informação, Belo Horizonte, v. 22, n. 3, p. 16-32, 2017.

COSTA, Camilla; DELLA BARBA, Mariana; IDOETA, Paula Adamo. Oscar 2015: Atrizes se rebelam contra o machismo no tapete vermelho. BBC News Brasil, São Paulo, 23 fev. 2015.

DAVIS, Angela. Mulheres, raça e classe. São Paulo: Boitempo Editorial, 2016.

FLUSSER, Vilém. O mundo codificado: por uma filosofia do design e da comunicação. São Paulo: Ubu Editora, 2017.

FLUSSER, Vilém. A Escrita: há futuro para a escrita? São Paulo: Annablume, 2010.

FOLHA DE S. PAULO. "José Mayer me assediou”. Folha de S. Paulo, São Paulo, 31 mar. 2017. \#Agoraéquesãoelas: um espaço para mulheres em movimento. Disponível em: 
https://agoraequesaoelas.blogfolha.uol.com.br/2017/03/31/jose-mayer-meassediou/. Acesso em: 03jun. 2021.

FOUCAULT, Michel. História da sexualidade. v. 1. A vontade de saber. Rio de Janeiro: Graal, 1985.

G1. Caso João de Deus: mulheres relatam abusos sexuais. G1, Rio de Janeiro, 10 dez. 2018. Goiás. Disponível em:

https://g1.globo.com/go/goias/noticia/2018/12/10/caso-joao-de-deus-mulheresrelatam-abusos-sexuais.ghtml. Acesso em: 03 jun. 2021.

G1. Mulher em estado vegetativo há mais de 10 anos dá à luz em clínica nos EUA; polícia investiga estupro. G1, Rio de Janeiro, 10 dez. 2018, 5 jan. 2019. Mundo. Disponível em:

https://g1.globo.com/mundo/noticia/2019/01/05/mulher-em-estado-vegetativoha-mais-de-10-anos-da-a-luz-em-clinica-nos-eua-policia-investigaestupro.ghtml. Acesso em 03 jun. 2021.

HISGAIL, Fani. Pedofilia. São Paulo: Editora Iluminuras, 2007.

HUECK, Karin. Depois de comentários pedófilos sobre o Master Chef Jr, mulheres compartilham no Twitter suas histórias de assédio infantil.

Superinteressante, São Paulo, 23 out. 2015. Disponível em:

https://super.abril.com.br/ideias/depois-de-comentarios-pedofilos-sobre-omaster-chef-jr-mulheres-compartilham-no-twitter-suas-historias-de-assedioinfantil/. Acesso em: 03 jun. 2021.

KOLTAY, Tibor. Library and information science and the digital humanities. Journal of Documentation, Bradford,v.72 n. 4, p. 781-792, 2016.

KRISTEVA, Julia. Poderes de la perversión: ensayo sobre Louis-Ferdinand Céline. Madrid: Siglo XXI, 1989.

MARTELETO, Regina Maria. Análise de redes sociais: aplicação nos estudos de transferência da informação. Ciência da informação, Brasília, v. 30, n. 1, p. 71-81, 2001.

OEIRAS, Janne Yukiko Y.; ROCHA, Heloisa V. Aspectos sociais em design de ambientes colaborativos de aprendizagem. In: ENCUENTRO

INTERNACIONAL DE INFORMÁTICA EN LA EDUCACIÓN SUPERIOR, 1., Habana. Anais[...]. Habana, 2001.

PARISER, Eli. O filtro invisível: o que a internet está escondendo de você. Rio de Janeiro: Zahar; 2010.

PEIXOTO, Adrielle Beze. Ciência e tecnologia e as alterações na forma de sociabilidade: um estudo sobre o software MSN Messenger. 2004. Dissertação (Mestrado em Sociologia) - Universidade Federal de Goiás, Goiânia, 2004. 
Disponível em: https://repositorio.bc.ufg.br/tede/handle/tede/3341. Acesso em: 03 jun. 2021.

PIMENTA, Ricardo M. Por que Humanidades Digitais na Ciência da Informação? Perspectivas pregressas e futuras de uma prática transdisciplinar comum. Informação \& Sociedade: Estudos, João Pessoa, v. 30, n. 2, 15 jun. 2020.

PRIMO, Alex. O aspecto relacional das interações na Web 2.0. E-Compós, Brasília, v. 9, 26 jun. 2007.

PRIMO, Alex Fernando Teixeira. O que há de social nas mídias sociais?: Reflexões a partir da teoria ator-rede. Contemporânea: Comunicação e Cultura, Salvador. v. 10, n. 3,set./dez., p. 618-641, 2012.

RECUERO, Raquel da Cunha. Teoria das redes e redes sociais na internet: considerações sobre o Orkut, os Weblogs e os Fotologs. In: Congresso Brasileiro de Ciências da Comunicação (INTERCOM), 27., 2004, Porto Alegre. Anais [...]. Porto Alegre, 2004.

RECUERO, Raquel da Cunha. Comunidades em redes sociais na internet: proposta de tipologia baseada no fotolog.com. 2006. Tese (Doutorado) - Curso de Doutorado em Comunicação e Informação, Universidade Federal do Rio Grande do Sul, Porto Alegre, 2006.

ROBINSON, Lyn, PRIEGO, Ernesto; BAWDEN, David. Library and information science and digital humanities: two disciplines, joint future? In: International Symposium on Information Science, 14., 2015, Zadar, Croatia. Proceedings [...]. Zadar, 2015.

ROMEIRO, Nathália Lima. Vamos fazer um escândalo: a trajetória da desnaturalização da violência contra a mulher e a folksonomia como ativismo em oposição a violência sexual no Brasil. Dissertação (Mestrado em Ciência da Informação) - Escola de Comunicação, Universidade Federal do Rio de Janeiro; Instituto Brasileiro de Informação em Ciência e Tecnologia, Rio de Janeiro, RJ, 2019.

ROMEIRO, Nathália; SILVA, Franciéle Carneiro Garcês. A folksonomia das hashtags como instrumento de militância contra o assédio sexual no facebook: avaliação da hashtag \#mexeucomumamexeucomtodas. Revista Brasileira de Biblioteconomia e Documentação, São Paulo, v. 14, n. 2, p. 215-232, 2018.

SAFFIOTI, Heleieth I. B. Violência contra a mulher e violência doméstica. Gênero, democracia e sociedade brasileira. São Paulo: FCC, 2002. v. 34.

SANTOS, Bruna Ribeiro Bonfim; SILVA, Letícia Machado; ZATTAR, Mariana.. Youtube como fonte de informação para o mercado de moda e 
beleza. Biblionline, João Pessoa, v. 12, n. 1, p. 86-95, 2016.

SILVA, Vitória Régia da. Com campanhas e hashtags, debate online sobre assédio quadruplica nos últimos três anos. 2018. Disponível em:

http://www.generonumero.media/com-campanhas-e-Hashtags-debate-onlinesobre-assedioquadruplica-nos-ultimos-tres-anos/. Acesso em: 03 jun. 2021.

SOUSA, Brisa Pozzi de.; SILVA, Flavio Pacheco da. Linguagem natural no Twitter e linguagem documentária em tesauros: da Hashtag \#NãoMereçoSerEstuprada ao descritor 169 estupro. Revista Ciência da Informação e Documentação, Ribeirão Preto, v. 6, n. 2, p. 20-43, set. 2015/fev. 2016.

SOUZA, Rosali Fernandes de. Organização do Conhecimento. In: TOUTAIN, Lídia Maria Batista Brandão (Org.). Para Entender a Ciência da Informação. Salvador: Edufba, 2007. p. 103-123.

\title{
Social media, violence against women and information: field prospection in the light of digital humanities
}

\begin{abstract}
This paper discusses the phenomenon of hashtags in digital social media as a strategy for discussing gender performances and resistance to violence against women. It seeks the theoretical and methodological reference of the Digital Humanities associated with those of Information Science and gender studies from the collection of data related to hashtags indexed \#primeiroassedio, \#meuprimeiroassedio and \#mexeucomumamexeucomtodas on facebook social media. Presents results characterized as "photos", "video", "report", "news" and "others". It identifies the category of photos that received the most interactions and sharing on facebook; which leads us to the concept of informational visibility. The importance of gender and information science and digital humanities research is understood, while the possibilities of discussing a topic that is sensitive not only for women but also for other strategies for forming networks of support, affection and social empowerment remain open.
\end{abstract}

Keywords: Violence against women. Social media. Digital Humanities. Hashtags. Gender Studies.

Recebido: 07/07/2020

Aceito: $21 / 12 / 2020$

\section{Declaração de autoria}

Concepção e elaboração do estudo: Nathália Lima Romeiro e Ricardo Medeiros Pimenta.

Coleta de dados: Nathália Lima Romeiro. 
Análise e interpretação de dados: Nathália Lima Romeiro e Ricardo Medeiros Pimenta.

Redação: Nathália Lima Romeiro e Ricardo Medeiros Pimenta.

Revisão crítica do manuscrito: Nathália Lima Romeiro e Ricardo Medeiros Pimenta.

\section{Como citar}

ROMEIRO, Nathália Lima; PIMENTA, Ricardo. Medeiros Mídias sociais, violência contra mulheres e informação: prospecção do campo à luz das humanidades digitais. Em Questão, Porto Alegre, v. 27, n. 4, p 107-136, 2021. Doi: http://dx.doi.org/10.19132/1808-5245274.107-136

1 Apesar de nos utilizarmos neste artigo do termo "Ciência da Informação" (CI), as contribuições de Lyn Robinson, Ernesto Priego e David Bawden (2010) e Tibor Koltay (2016) se referem ao mesmo campo como "Library and Information Science" (LIS), o que epistemologicamente deveria ser traduzido no Brasil para "Biblioteconomia e Ciência da Informação" (BCI). É visível que no Brasil não há consenso claro sobre o melhor termo assim como aparetentemente há um certo descaso para com a manutenção do termo biblioteconomia como hierarquicamente paralelo e não circunscrito à, então, CI. Por motivos de origem disciplinar e institucional, manteremos o termo CI em detrimento a BCI no corpo deste artigo, reconhecendo a necessidade futura de maiores debates sobre essa questão.

${ }^{2}$ Tradução livre dos autores: An integration between LIS and those strands of DH which have an explicit interest in the components of the information chain seems to offer a positive future for both disciplines. Not merely does it cement a natural alliance between disciplines with similar concerns and perspectives, (...) but it allows for new research approaches at the interface of the two disciplines. Examples of the latter are the extension of bibliometric studies with DH approaches to give greater insight (Sula, 2012) and analysis of social media, with the same benefits.

3 Tradução livre dos autores: both LIS and DH can be considered to be "sciences of information", i.e. disciplines that are interested in the study of information (...) DH is struggling to understand the effects of a growing digital infrastructure as a system for knowledge production in the humanities. Such thinking may be extended to the act of looking at the digital component of the DH by thinking critically about the ways, how knowledge in the twenty-first century is transformed into information through computational techniques. In this process, computational devices require a given object be translated into the digital code that the computer can understand. [...]This goal is not just meaningful, but fundamental for both disciplines.

4 Tradução livre dos autores: "there are essential and irreplaceable gains to be had by the application of digital tools to the project of interpreting (and reinterpreting) the human record for the edification of society. To a disconcertingly large number of outsiders, the digital humanities qua humanities remains interesting but irrelevant. Anthony Grafton speaks for the majority when, in a recent New York Times piece (Cohen), he repeats the platitude that the digital humanities is a means and not an end". 